\title{
Comunidad, conectividad y movimiento regional en la Patagonia: evolución del capital social en la Región de Aysén, Chile
}

\author{
John W. Durston, José Manuel Gaete y Miguel Pérez
}

Resumen

Las pequeñas comunidades rurales de la Región de Aysén, Chile, evidencian una variedad de formas y tipos de capital social. La forma específica de capital social que predomina ha evolucionado según cambios en el contexto nacional y la progresiva integración comunicacional. Tras haber sido ejemplo de cooperación comunitaria, las comunidades rurales enfrentaron el desafío de relacionarse con actores sociales de mayor poder, en el escenario ampliado de la sociedad civil regional. En muchos casos, este cambio conllevó una menor autonomía y la captura de facciones comunitarias en cadenas de clientelismo. Sin embargo, en 2012 emergió el movimiento "Tu problema es mi problema" para enfrentar la marginación percibida en sus relaciones asimétricas con el gobierno central. Este evento masivo de desobediencia civil se basó en tres formas de capital social y marcó la emergencia de una ciudadanía de alcance regional, cumpliendo una de las condiciones para una descentralización plenamente democrática.

PALABRAS CLAVE

CLASIFICACIÓN JEL

AUTORES
Desarrollo rural, capital social, desarrollo de la comunidad, participación comunitaria, Internet, Chile

Z130, R580, R500

John W. Durston Ph.D. en Antropología London School of Economics and Political Science. 1johndurston@ gmail.com

José Manuel Gaete es Investigador Postdoctoral del Fondo Nacional de Desarrollo Científico y Tecnológico (Fondecyt) y del Centro de Estudios del Desarrollo Regional y Políticas Públicas (ceder) de la Universidad de Los Lagos, Chile. josemanuel.gaete@ulagos.cl

Miguel Pérez es Profesional del Fondo de Innovación para la Competitividad/Máster en Gestión y Políticas Públicas División de Planificación y Desarrollo Regional (DIPLADE), Gobierno Regional de Aysén. mperez@goreaysen.cl 


\section{I}

\section{Introducción}

El capital social es un recurso intangible desarrollado por las personas y los actores colectivos para sus emprendimientos, no solo en comunidades tradicionales sino también en sociedades modernas. Sus atributos básicos — confianza, reciprocidad difusa y cooperaciónson contrarios a los principios del mercado, pero constituyen activos actores en este, al igual que en la sociedad civil.

Durante más de dos décadas, el concepto de capital social ha atraído la atención de académicos y diseñadores de políticas debido a sus implicancias para el desarrollo económico y la gobernanza. Las investigaciones y propuestas se han centrado en dos aspectos: la importancia de las redes en las estrategias de las personas, y las posibilidades de las pequeñas comunidades de aplicar este activo intangible en sus estrategias como actores en el mercado y en la sociedad civil. El presente estudio de caso se concentra en la interacción entre estas dos formas - personal y colectiva - de capital social en el campo de la sociedad civil. En él se combina información disponible en la literatura profesional relativa al capital social, la sociedad civil y los movimientos sociales con información empírica sobre la Región de Aysén.

Las preguntas centrales en este artículo son dos: ¿cuáles formas de capital social estuvieron en auge en diferentes épocas en la Región de Aysén?, y iqué implicancias tienen para la descentralización las formas de capital social en torno del reciente movimiento regional? El objetivo final de la metodología aplicada es dar cuenta del papel del capital social en una emergente sociedad civil a nivel regional.

Se seleccionaron siete comunidades rurales que ejemplificaban una diversidad de situaciones de aislamiento (véase el cuadro 1), de población y geográficas. En ellas se aplicó una encuesta ${ }^{1}$ a 493 usuarios de Internet, con una omisión estimada menor del $5 \%$. Se visitó cada hogar hasta tres veces en sucesivos días para

Este artículo forma parte del proyecto del Fondo Nacional de Desarrollo Científico y Tecnológico (FONDECYT) (No 1120866), "El impacto de Internet en el capital social de las comunidades aisladas". ${ }^{1}$ La Encuesta de Usuarios Rurales de Internet se realizó durante 2012 como parte de la presente investigación en las pequeñas comunidades que se señalan en el cuadro 1 . Se visitó cada hogar hasta tres veces en sucesivos días para entrevistar a todos los usuarios que habían accedido a Internet durante la semana anterior a la entrevista. entrevistar a todos los usuarios que habían accedido a Internet durante la semana precedente a la entrevista.

Se aplicó una metodología de análisis de aglomeraciones productivas (clusters) de usuarios de Internet mayores de 25 años. La técnica utilizada para la elaboración de esta tipología es un análisis de cluster de dos etapas que opera dividiendo ene casos en un conjunto de grupos donde: i) un caso pertenece a solo un grupo, y ii) el conjunto de grupos contiene todos los casos que son objeto de la clasificación. El cumplimiento de estos principios supone una distancia/diferencia intragrupo menor que la distancia/diferencia entre grupos, hecho que para el caso de la clasificación en dos etapas supone obtener un coeficiente de silueta igual o superior a 0,6.

Se aplicaron los instrumentos cualitativos y las estrategias del método sociológico inductivo de la teoría fundamentada (grounded theory). Se utilizan entrevistas abiertas sobre la base de unas preguntas de estudio muy generales, en lugar de delimitar variables independientes y dependientes (y excluir el resto de la información del entorno). Las hipótesis emergen mientras se acumula información, sin pretensión de "probarlas". La iteración entre comparación, generación de hipótesis y vuelta al terreno implica también cuestionamientos a la literatura teórica. La última etapa del proyecto de investigación concentra el esfuerzo de generar nuevas interpretaciones de valor teórico o de implementación en políticas públicas, siempre tratando de mantenerse muy cerca de la base empírica.

Las prácticas, relaciones y procesos detectados mediante estas técnicas cualitativas ejemplifican fenómenos que permiten desarrollar modelos de interpretación, pero no representan el peso cuantitativo que puede tener un fenómeno en la población total. Para este propósito, se confrontó la información cualitativa con los datos numéricos, emergiendo nuevas hipótesis sobre la relación entre conectividad y capital social.

El artículo se desarrolla de la siguiente manera. Luego de esta Introducción, en la sección II se abordan los debates, definiciones y la diversidad en torno del capital social. En la sección III se examinan la conectividad y el capital social comunitario en zonas aisladas de Aysén. Por su parte, la sección IV se enfoca en el movimiento regional y en el papel que juegan el capital social y el Internet en este escenario. Finalmente, la sección V contiene las principales conclusiones derivadas del estudio. 


\section{II}

\section{Capital social: debates, definiciones y diversidad}

Las relaciones interpersonales y las organizaciones socioculturales contienen capital social cuando convierten normas de reciprocidad, identidad y solidaridad en prácticas de cooperación y ayuda mutua. La repetición de estas prácticas retroalimenta tales normas a la par que hace aumentar la confianza entre las personas involucradas. En conjunto, estas facetas del capital social posibilitan emprendimientos en todos los campos, aumentando la probabilidad de lograr objetivos que estarían fuera del alcance de un individuo por sí solo.

Durante la última década del siglo xx y el primer lustro del siglo actual, el debate sobre el concepto de capital social recorrió el mundo de las políticas sociales. Incluso se puso de moda entre un público más amplio, con el éxito del libro Making Democracy Work (Putnam, 1993). Asimismo, adquirió una importancia probablemente desmedida en las discusiones de la superación de la pobreza y el desarrollo participativo, llegando a extremos de hipérbole como en el caso de la publicación del Banco Mundial, que planteó que el capital social podría ser el "eslabón perdido" del desarrollo (Grootaert, 1998). Para la mayoría de los analistas, la existencia de estas capacidades colectivas de actores sociales populares fue una razón para potenciar este recurso intangible, mediante el aporte de mayores recursos públicos a emprendimientos grupales autogestionados.

Hasta entonces, la relevancia misma para el desarrollo de los temas de asociatividad y cooperación había estado en duda, en parte debido al supuesto axiomático de la maximización de ganancia del actor individual en los modelos económicos. Hardin reforzó el argumento en contra de la posibilidad de cooperación y acción colectiva en un sistema de mercado moderno: en su trabajo de 1968, The tragedy of the commons, planteó que el interés individual de cada actor condenaba al agotamiento de recursos económicos tenidos en común, como las zonas de pastoreo comunitarios. Esto cambió, para muchos, con la publicación de El gobierno de los bienes comunes (Ostrom, 2000).

Elinor Ostrom, única mujer ganadora del Premio Nobel en Economía, analizó miles de casos de gestión comunitaria de bienes comunes y llegó a poner en duda los argumentos teóricos de Hardin. Como dice Uphoff (2003), el trabajo de Ostrom sirve "para explicar la gran cantidad de acciones colectivas que en los hechos ocurren y perduran". Los estudios de Ostrom toman plenamente en cuenta la elección racional (rational choice) del individuo y, por ende, enfatizan el papel de las reglas en la gestión colectiva sustentable para evitar la traición ante tentaciones de beneficio personal. Pero también tienen en cuenta el sentimiento de ser artífices de su propio destino y las normas culturales que premian con prestigio las conductas de servicio al grupo.

\section{Dos tipos de capital social}

Una de las principales manifestaciones del capital social es la formación de organizaciones de la sociedad civil (Putnam, 1993; Molenaars, 2006). Otra es la formación de extensas redes de vínculos personales, que también influyen en la vida cívica (Portes, 1998). Son dos tipos diferentes de participación de las personas en la sociedad civil de su comunidad y de su país. Su interacción determina, en gran medida, el papel de diversas formas de capital social en la dirección que toma la sociedad civil en un territorio dado.

La distinción es importante, ya que el capital social personal consiste en el vínculo recíproco, o diádico, entre dos personas y las redes compuestas de estos vínculos; mientras que el colectivo asume formas más organizadas, con división de trabajo, legitimación de líderes y control social de los integrantes. En cada caso concreto de organización, los lazos y lealtades interpersonales pueden hacer que una organización de base funcione mejor cuando los recursos a los que dan acceso son puestos por la persona a disposición de la colectividad. Pero tales vínculos personales también pueden desviar los recursos de esas organizaciones hacia objetivos más mezquinos, dañando la confianza de la colectividad. La separación de los dos conceptos es un avance, ya que las definiciones de capital social de principios de los años noventa (por ejemplo, Putnam, 1993) mezclaban diferentes niveles de análisis (valores, prácticas, resultados) y no distinguían entre diferentes formas de capital social. 


\section{Organizaciones}

Las primeras formulaciones de capital social como categoría analítica, hace alrededor de un siglo, se centraban en su forma comunitaria colectiva. El gran teórico de la educación, John Dewey, también fue fundador del uso teórico-académico del término a finales del siglo XIX (véase Farr, 2004). En sus escritos y en los de uno de sus seguidores, Lyda Hanifan, se desarrolla una definición claramente colectiva:

"[capital social refiere a] la buena voluntad, la fraternidad, la compasión y el intercambio social entre los individuos y las familias que componen una unidad social, la comunidad rural... este capital social puede ser dirigido fácilmente hacia la mejoría general del bienestar comunitario" (Hanifan, 1920). No toda organización formal tiene capital social alto, ese activo intangible e informal. En muchas organizaciones que existen "en el papel", las prácticas de los socios no siguen las normas informales de solidaridad y honra. Tampoco son estables en el tiempo los grupos informales sin reglas formales claras. Ostrom enseña que el capital social requiere de organización formal para hacer frente a objetivos mayores de gestión, como también para excluir a los beneficiarios gratuitos (free riders) mediante reglas con respecto a quiénes son miembros y cuáles son sus derechos, y establecer sanciones graduales a los que trasgreden las reglas dependiendo de la gravedad de la falta (Ostrom, 2000).

Con la acumulación de estudios empíricos y su análisis, los alcances y límites del capital social colectivo han quedado más claros (Atria, 2003), estableciéndose como uno de los conceptos clave de un nuevo marco analítico del "desarrollo en la base" (grass-roots development). No obstante, el capital social es solo un activo, entre muchos, que poseen las personas y las colectividades y que emplean en estrategias de mejoramiento de sus posiciones sociales.

El capital social tiene otros aspectos relevantes: es siempre un activo para sus propietarios, pero no siempre es bueno para la sociedad en general. Hoy es claro que el poder es un eslabón clave de este marco conceptual que se hallaba "perdido" para muchos estudiosos del tema en los años noventa. El uso por parte de las élites de sus redes personales para excluir a grandes sectores de la población de la toma de decisiones de interés público fue estudiado en Francia, en gran detalle empírico y teórico, por Pierre Bourdieu. Este autor desarrolló su concepto de "capital social" ya en la década de 1970 (Bourdieu y De Saint Martin, 1978). Su visión del tema abarcaba aspectos no considerados por Hanifan, como tampoco posteriormente por Putnam. Bourdieu y sus seguidores relacionan el capital social con la pugna por controlar campos de poder entre diferentes redes de dueños de empresas o bancos y altos funcionarios públicos. En los términos relevantes de su extenso y disperso modelo de capital social también se incluyen, por ejemplo, los patrones compartidos de conductas basadas en la experiencia (el habitus) que refuerzan las identidades de clase, las relaciones heredadas, el capital cultural y escolar (compañeros de estudio) y los modos de dominación (Bourdieu, 2001). Su importancia en este punto es que obliga a pasar del capital social como "recurso de los pobres" al capital social como un recurso de la competencia entre todos los actores. En este modelo, la sociedad civil y el Estado están compenetrados por vínculos entre aliados, y por las luchas entre grupos rivales para controlar el campo de las políticas públicas.

Esta visión, en la que se incorpora la desigualdad de poder, hace una distinción entre actores que ocupan posiciones sociales de poder similar, con vínculos "simétricos" u "horizontales", y el capital social asimétrico, como el clientelismo político, que vincula a personas de posiciones desiguales.

El clientelismo político, en términos simples, es el intercambio de "favores por votos", pero tiene otras facetas relevantes que lo convierten en una forma de capital social: i) el vínculo entre personas, y ii) su función como extensión "hacia arriba" de las redes microlocales tradicionales en sectores populares de ayuda recíproca. En resumen, el clientelismo es una forma "personalizada" (Auyero, 2001), "asimétrica" e "interclase" de inclusión social de personas y comunidades subalternas (literalmente "los otros de abajo"). Como todos los otros vínculos de capital social interpersonal, el clientelismo se refuerza simbólicamente con gestos de una amistad (real o fingida) (Wolf, 1966). Asimismo, facilita a los estratos populares el acceso a recursos controlados por estratos privilegiados, principalmente a los recursos públicos. Hay una importante variedad de roles y relaciones que responden a diferentes situaciones de clientelismo político, desde el papel de "caudillo" hasta el de "reformista semiclientelar" (Fox, 1996).

Finalmente, se hace una distinción entre un capital social popular "activo" y un capital social "subsidente"3 que sobrevive en forma latente, como memoria social,

\footnotetext{
2 También conocido como capital social de puente (bridging social capital), que establece un vínculo entre pares de distintos grupos o localidades (Woolcock y Narayan, 2000).

${ }^{3}$ Del verbo inglés to subside, término que evoca el período de bajamar de las mareas.
} 
cuando las condiciones del entorno le son adversas (Salazar, 2001).

En este trabajo se utilizan varios de estos conceptos dicotómicos de capital social: personal y colectivo, activo y subsidente, simétrico y asimétrico. El estudio en la Región de Aysén permite iluminar algunos aspectos de esta complejidad conceptual y empírica en contextos de creciente integración y conectividad.

\section{III}

\section{Conectividad y capital social comunitario}

\section{en zonas aisladas de Aysén}

La Región de Aysén, en la Patagonia chilena, es una de las 15 regiones administrativas y electorales del país. Aysén se caracteriza por una baja densidad poblacional, clima lluvioso y frío, extensos bosques y relieves geográficos abruptos. En su conjunto, estas condiciones terminan por dibujar un espacio geográfico difícil de transitar y habitar y, también, de conectar.

El objetivo de esta sección es entender mejor cómo la progresiva superación del aislamiento ha contribuido a cambios en las formas de capital predominantes en comunidades rurales de la Región de Aysén (véase el cuadro 1).

CUADRO 1

Grados de aislamiento de las comunidades estudiadas en la Región de Aysén

\begin{tabular}{ll}
\hline Quintil & Comunidades \\
\hline 1 (20\% más aisladas) & Villa O’Higgins \\
2 & Lago Verde, Puerto Tranquilo \\
3 & Villa Amengual, Caleta Tortel \\
4 & Puerto Ibáñez, Cerro Castillo \\
5 (20\% menos aisladas) & ----- \\
& Universo $=52$ localidades habitadas
\end{tabular}

Fuente: Elaboración propia sobre la base de Subsecretaría de Desarrollo Regional (SUBDERE), "Metodología para la identificación de localidades en condición de aislamiento", Santiago, 2013 [en línea] http://www.subdere.gov.cl/sites/default/files/documentos/ metodologia_03072013.pdf.

Las siete comunidades varían en tamaño entre aproximadamente 300 y 800 habitantes cada una. También ejemplifican una diversidad de variables geográficas y económicas.

El término conectividad se utiliza a menudo para referirse a la comunicación rápida de información entre computadores y otros medios nuevos como los teléfonos móviles. Son las llamadas tecnologías de la información y las comunicaciones (TIC ) "modernas". Aquí sin embargo se utiliza el término conectividad en sentido amplio, para incluir no solo Internet sino, por una parte, las TIC "tradicionales" (radio, teléfono, televisión) y, por otra, todas las formas de integración territorial (transporte de mensajes, personas y bienes por tierra, agua y aire); en suma, todos los avances que reducen el aislamiento.

A continuación se postula, primero, que el aumento de la conectividad en sentido amplio ha tenido impactos de diverso signo en el capital social comunitario (o sea, colectivo y local) rural, y asimismo, ha significado la reducción del aislamiento histórico de la región. Segundo, que las comunidades rurales de Aysén ya han vivido tal proceso en forma constante durante al menos medio siglo. $\mathrm{Y}$ tercero, que formas personalizadas y asimétricas de capital social reemplazaron a gran parte de las formas comunitarias en el campo de la sociedad civil. Por último, que la densificación en el territorio regional de una masa crítica de organizaciones de base, junto con la imbricación de las TIC clásicas con las modernas, hicieron posible un exitoso movimiento social regional.

El primer postulado parte de los argumentos teóricos y las evidencias empíricas de otros países. Wellman (2005) plantea, en primer término, que con la extensión del telégrafo y otros inventos del siglo xIX se liberó a la comunicación de las limitaciones del transporte; y en segundo lugar, que hoy la mayoría de las personas en el Canadá y los Estados Unidos de América se relacionan más en redes extracomunitarias que con sus vecinos locales. Tercero, el autor argumenta que estos cambios conducen a que las personas sientan menos compromiso con la comunidad, que esta tenga menos control sobre las conductas de dichas personas y que se reduzcan los sentimientos de pertenencia, membresía e identidad con el grupo local. Internet, en particular, ha aumentado la oportunidad, la contingencia y la incertidumbre de las relaciones entre personas, en comparación con el viejo contexto de grupos locales. 
Las primeras formulaciones del capital social comunitario ocurrieron en los Estados Unidos de América hace casi un siglo. Hanifan (1920) notó con preocupación que el ferrocarril, el telégrafo, el teléfono y el automóvil habían acelerado el éxodo rural en la primera posguerra, debilitando el tejido social de las comunidades rurales. Frente al desafío de la progresiva desaparición de actividades comunitarias rurales, Hanifan proponía el desarrollo de una completa estrategia de centros comunitarios para reconstruir el capital social de las comunidades dañado. Si bien existe una enorme distancia entre la realidad de Aysén y la estadounidense de antaño, tampoco es novedad la tendencia casi universal de que la expansión de la conectividad conduce a la desaparición de muchas comunidades rurales. En Aysén, la evolución difiere de comunidad en comunidad, pero debe notarse que estas han experimentado en forma casi simultánea los impactos de las TIC de un siglo atrás (teléfono, radio) con las TIC del siglo XXI, en una transformación intensa y acelerada.

\section{IV}

\section{Capital social y conectividad: épocas y transiciones}

Durante los últimos 50 años, el desarrollo de la conectividad y la transformación del capital social en el campo aysenino se pueden dividir en tres épocas que corresponden a mejoras en la conectividad y a cambios en la relación entre las comunidades rurales de la región y el gobierno central.

\section{a) Época de 1964 a 1973}

Hacia 1964 (inicio del gobierno reformista de la Democracia Cristiana), el Estado ya había establecido una cobertura básica de la conectividad de la región en materia vial, fluvial, marítima, aérea y de correos y teléfonos (Martinic, 2005). Tempranamente se difundió la radio en cuanto se contara con electricidad (inicialmente, mediante baterías de auto o miniturbinas de agua). De manera rápida, la radio llegó a ser la principal vía de información, de mensajes personales y de conversación en tiempo real ${ }^{4}$. En los años sesenta, las huellas para transporte a caballo se ampliaron gradualmente a caminos para carretas, que fueron utilizados por los primeros vehículos motorizados (Universidad de Los Lagos/ Centro de Análisis de Redes Sociales, s/f).

Aun descontando el sentimiento casi universal de que "cada tiempo pasado fue mejor", las entrevistas en profundidad han dejado en claro la cantidad de emprendimientos solidarios en el interior de cada

\footnotetext{
4 La radio de onda corta, una tecnología "antigua" en contraste con la telefonía móvil o Internet, permitió la subjetividad dialogante en Aysén hace más de medio siglo.
}

comunidad estudiada, hace una generación atrás. Existe constatación histórica, por ejemplo, de las prácticas de autoconstrucción colectiva y gratuita de escuelas. En los casos en que se necesitaba dinero para concretar un emprendimiento comunitario se solían realizar "beneficios bailables", a los que venían personas de otras comunidades, a veces a dos días de marcha. En el baile se conocían jóvenes de las diversas comunidades en cada microrregión y se formaban parejas. Hoy tales eventos se hacen solo con participantes locales, para ayudar a un vecino en gastos médicos o después de un incendio, pero la práctica antigua dejó una red de parentescos en las comunidades de la región (Universidad de Los Lagos/Centro de Análisis de Redes Sociales, s/f). Por otra parte, en las cinco comunidades estudiadas, según la Encuesta de Usuarios Rurales, el 34\% de los usuarios nacieron en otra comuna de la Región de Aysén. En cada comunidad, entonces, hay vínculos de parentesco a través de la región.

Como en todo el país, en Aysén este fue un período de grandes cambios en las comunidades rurales: Reforma Agraria durante los gobiernos de Frei Montalva y de Allende, sindicalización y polarización ideológica de la sociedad civil. Las propuestas de organización de orientación católica y de izquierda compitieron en la creación de juntas de vecinos y comités de pequeños agricultores (a través del Instituto de Desarrollo Agropecuario (INDAP)), y en la inscripción de votantes. Muchos habitantes de comunidades rurales ayseninas se beneficiaron de la Reforma Agraria y de los servicios de extensión para cooperativas campesinas impulsados por estas dos administraciones. 
La conectividad de la década de 1960 mejoró la capacidad del Estado en el empoderamiento de las comunidades rurales mediante la formalización de sus derechos y asesoría como organización. Los comités de pequeños agricultores creados por los primeros extensionistas idealistas del INDAP asumieron papeles de actores sociales diversos, como vecinos y no únicamente como agricultores. El capital social colectivo de la pequeña comunidad se vio complementado y también complejizado debido a la creciente presencia de formas asimétricas no solo de clientelismo político, sino también de expresiones más solidarias de capital social.

\section{b) Vínculos asimétricos solidarios}

Los extensionistas idealistas y funcionarios de la Reforma Agraria del período 1964-1973 fueron aliados de los habitantes de las comunidades rurales de Aysén, desde posiciones sociales superiores en el campo de las relaciones Estado-ruralidad. Las cooperativas de comercialización de la lana apoyadas por el INDAP en aquella época forman parte aún de la memoria social en las comunidades estudiadas por el ya mencionado proyecto del Fondo Nacional de Desarrollo Científico y Tecnológico (FONDECYT). Las relaciones personales entre los líderes locales y extensionistas profesionales conectaban a dichos líderes con los directores de las oficinas regionales y con los partidos en el gobierno a niveles regional y central. El sentido de misión de muchos de estos extensionistas les hizo poner sus contactos al servicio de los líderes locales, los que se beneficiaron en prestigio en cuanto aportaban a mejorar la calidad de vida de todos los vecinos (Astorga, 2007; Universidad de Los Lagos/Centro de Análisis de Redes Sociales, s/f).

\section{c) Época de 1973 a 1989}

Después del golpe militar de 1973, la Reforma Agraria quedó truncada, mientras que el resto de esa década y toda la siguiente estuvieron marcados por la presencia militar en toda la región en varios niveles del Estado y la sociedad civil. En Aysén, las telecomunicaciones fueron clave en la "seguridad interior" y en la defensa ante una posible invasión argentina. También aseguraron la casi ausencia de opositores al gobierno de facto en las organizaciones regionales de la sociedad civil. Junto con la eliminación física de muchos dirigentes, el Estado promovió la creación de Juntas de Vecinos con dirigentes adictos al régimen. Estos ayudaban a destinar el reparto de bienes, un importante y nuevo papel también para los alcaldes designados por el jefe de Estado.

La Carretera Longitudinal o Austral (originalmente llamada "Presidente Augusto Pinochet"), aporte emblemático del Ejército a la conectividad en la región, sirvió de vía de emigración para muchos colonos empobrecidos y de entrada para empresas forestales, pesqueras, de transporte y turismo. Hacia 1970 hubo alrededor de 1.000 kilómetros de camino vehicular público. En 1976 se dio inicio a los trabajos de ampliación por parte del Cuerpo Militar del Trabajo. Incluida la red de caminos transversales, 1.283 kilómetros fueron construidos entre 1976 y 1989, llevando el total a 2.300 kilómetros. Hoy, la red es de unos 3.500 kilómetros.

La división de la región en un número mayor de comunas y la designación en ellas de alcaldes por el gobierno militar iba en procura de mayor apoyo a su estrategia geopolítica en la Patagonia chilena ${ }^{5}$, pero al mismo tiempo se perdió la iniciativa de la acción colectiva en las comunidades de Aysén y comenzó una relación asistencialista, de capital social asimétrico, con personas en posiciones de poder por sus relaciones con el Estado central:

“... durante la dictadura, se dieron muchos subsidios y se puso en práctica la entrega de muchas cosas, en especial de canastas familiares. Así, la gente se fue acostumbrando a asistir a reuniones solo para pedir o recibir subsidios..." (Vecino de comunidad rural de Aysén, en Astorga, 2007).

La segunda mitad de los años setenta fue un período de desánimo en las comunidades rurales de Aysén ${ }^{6}$, ya que la política del gran freno a la economía y el empleo (el tratamiento de shock antiinflación) coincidió con el colapso del precio mundial de la lana, crisis de la que los colonos ovejeros de Aysén nunca se recuperaron. Se inició así, a principios de los años ochenta, un éxodo en busca de empleo y de educación.

En forma inicialmente clandestina y con la llegada de las nuevas empresas, volvió a emerger el sindicalismo como actor popular con capital social colectivo, especialmente en el sector pesquero. Pero, en general, el período de la dictadura ocasionó una destrucción de capital social, tanto personal (por la pérdida de

\footnotetext{
${ }^{5}$ Hoy, el Ejército sigue siendo un actor importante en la región, en función del concepto geopolítico de soberanía efectiva: "La participación del Ejército cooperando con el desarrollo de las zonas aisladas y extremas... ha sido un asunto de preocupación permanente... Debemos mejorar nuestra capacidad de control en los espacios vacíos, ya que, de lo contrario, otro actor o amenaza tenderá a ocupar o sacar ventaja de ello". Comandante en Jefe del Ejército (Ejército de Chile, 2013).

${ }^{6}$ Una excepción fue el Padre Antonio Ronchi, quien a juicio de los entrevistados fue otro motor para la organización de las comunidades, puesto que estimuló la formación de organizaciones comunitarias para la realización, con recursos locales, de infraestructura comunicacional. Entre muchas otras obras, su asesoría predominó en la construcción comunitaria de antenas satelitales de televisión.
} 
confianza) como colectivo (debido a la represión de las organizaciones). Para el mundo rural en Aysén fue entonces un período de capital social "subsidente" (Salazar, 2001) por excelencia.

\section{d) Época de 1990 a 2013}

El fin de la dictadura militar a partir del plebiscito de 1988 abrió las puertas a elecciones libres y a la asociatividad de base. Mejoraron las condiciones para sindicatos y organizaciones locales y aumentaron los recursos del Estado central destinados a las organizaciones comunitarias, en parte a través de los alcaldes elegidos. No obstante, esta expansión de la sociedad civil fue canalizada por los partidos de las dos principales coaliciones electorales, que se alternaron en el poder en los últimos años.

Continuó la expansión de la red vial, del transporte aéreo, la televisión y las radioemisoras, y empezó la difusión de las TIC modernas, como es el caso de los teléfonos móviles. Gracias al bajo precio (subvencionado por las empresas proveedoras) de los aparatos, su uso se propagó rápidamente, sobre todo a partir de 2010, con la construcción de nuevas antenas.

En cuanto a Internet, algunas comunidades contaban desde hacía varios años con al menos un cibercafé o centro comunitario con servicio satelital o con un módem fijo. Pero con la llegada de la telefonía móvil, los propietarios de computadores podrían conectarse a Internet desde sus casas o lugares de trabajo, por medio de la señal 3G.

En los años posteriores a la dictadura, la relación asimétrica personalizada y solidaria entre la comunidad y funcionarios con una mística de vocación fue desarrollada por los jóvenes profesionales de Servicio País (Universidad de Los Lagos/Centro de Análisis de Redes Sociales, s/f), un programa de apoyo a municipalidades, rurales en su mayoría. El sentido de misión de muchos de estos funcionarios les hizo poner sus contactos al servicio de los líderes locales. Las relaciones personales entre dichos líderes y estos profesionales conectaban a los primeros con los directores de varios servicios públicos regionales. Los líderes locales se beneficiaban en prestigio en la medida en que aportaran a mejorar la calidad de vida de todos los vecinos.

\section{e) Vínculos clientelares}

No siempre la presencia de agencias del Estado ha significado más capital social y mayor poder para las comunidades rurales de Aysén. El clientelismo electoral no es una práctica nueva, ni propia de Aysén, sino universal en las democracias representativas. Los líderes que tenían contactos (pitutos, en chileno coloquial) y aliados en el mundo de los partidos políticos y de la burocracia estatal eran, para sus vecinos, amigos que resolvían los problemas que estos tenían con diversos servicios públicos (Auyero, 2001). Los líderes de tipo "gestionador" son intermediarios (brokers) (Valenzuela, 1977) que "gestionan" solicitudes a través de estos vínculos verticales. Sus gestiones para resolver problemas locales comprometen las intenciones de voto de las comunidades. Al contrario de los extensionistas con vocación, los brokers políticos no suelen aportar al empoderamiento de organizaciones de base, sino a sus propias carreras políticas.

Si bien la falta de conectividad limitó la penetración clientelar en la primera época de comunidades aisladas, ya en 2012-2013 los alcaldes fueron los brokers más mencionados (Universidad de Los Lagos/Centro de Análisis de Redes Sociales, s/f). Ellos podrían dar empleos públicos a sus seguidores o, de una manera más sutil, designar a sus funcionarios como asesores que ayudaban a formular buenas postulaciones a fondos de desarrollo, respecto de aquellas comunidades cuyos líderes les aseguraban sus votos (Universidad de Los Lagos/ Centro de Análisis de Redes Sociales, s/f). En Puerto Tranquilo y en Puerto Bertrand, pequeñas comunidades del interior, Astorga (2007) encontró que:

"La gente se agrupa y deposita sus necesidades en el dirigente, quien es el responsable de hablar con las autoridades y expresarles las preocupaciones de la comunidad. Esto entrega al dirigente un nuevo rol y poder dentro de la comunidad, se transforma en la persona que tiene la capacidad de contactar a la comunidad con esferas 'más altas"' (Astorga, 2007). En 2013, la investigación cualitativa detectó más dirigentes clientelares que líderes participativos que rendían cuentas a sus bases. La supervivencia de algunas formas participativas tradicionales chocó con el aumento de relaciones clientelares. Estas dos formas contrarias de capital social en las comunidades rurales de Aysén se tradujeron en crecientes divergencias entre sus moradores.

f) Impacto de Internet en las comunidades rurales

Aunque la mayoría de las comunidades rurales de Aysén estudiadas solo tuvieron acceso amplio a Internet en 2011 o 2012, en general, ya hubo indicios en este último año de al menos cuatro cambios en el capital social que pueden relacionarse con esta TIC.

Primero, según los entrevistados, las personas tienden a quedarse más en sus propias casas y comunicarse entre ellos por Facebook, disminuyendo los encuentros cara a cara: 
“... la tradición de ir a la casa, de tomarse el mate, de conversar acerca de las cosas cotidianas se fue perdiendo producto de esta posibilidad de establecer una comunicación digital" (Universidad de Los Lagos/Centro de Análisis de Redes Sociales, s/f).

En segundo lugar, el celular e Internet constituyen medios de autonomía e independencia para establecer contactos económicos hacia el exterior.

Tercero, mediante esta tecnología los vecinos pueden depender menos de los líderes que antes eran los brokers entre ellos y el mundo más amplio, porque pueden acceder directamente a información que dejó de ser monopolio de líderes con contactos. Ahora muchas personas pueden establecer sus propios vínculos de capital social, tanto horizontal de puente con pares distantes como de contacto con funcionarios públicos y otras personas de mayor poder. Este empoderamiento amplio empieza a reducir la asimetría en las relaciones de clientelismo político.

No es que haya en la región menos capital social hoy que antes, sino que el capital social producido por las TIC modernas no suele ser comunitario sino personal (sobre este mismo fenómeno en otros países, véanse Foth, 2003; Ferlander y Timms, 2007). No es raro, entonces, que en 2013 solo el $48 \%$ del total de usuarios de Internet participaban en organizaciones locales. Sin embargo, dentro de esta tendencia general, los entrevistados se dividen en tres conglomerados (clusters) con conductas y actitudes bien diferenciadas:

i) participativos simples (no usan Internet, pero tienden a participar en organizaciones locales);

ii) cibernautas (ocupan Internet con frecuencia, pero participan menos en organizaciones locales. Tienden a ser más jóvenes y más instruidos que los de otros dos clusters).

iii) cibernautas-participativos (utilizan Internet frecuentemente y también participan en organizaciones locales).

Así, por ejemplo, los cibernautas-participativos (alrededor de un tercio de los usuarios) están de acuerdo en un 93,3\% (más que los otros dos conglomerados) con la frase "Me siento parte de la comunidad" (véase el cuadro 2).

Indique el grado de acuerdo o desacuerdo

\begin{tabular}{|c|c|c|c|c|c|}
\hline & & \multicolumn{3}{|c|}{ Me siento parte de la comunidad } & \multirow[b]{2}{*}{ Total } \\
\hline & & En desacuerdo & $\begin{array}{l}\text { Ni de acuerdo } \\
\text { ni en desacuerdo }\end{array}$ & De acuerdo & \\
\hline \multirow[t]{4}{*}{ Participativos } & $\mathrm{N}$ & 4 & 2 & 51 & 57 \\
\hline & $\%$ Fila & 7,0 & 3,5 & 89,5 & 100,0 \\
\hline & $\%$ Columna & 11,8 & 6,9 & 18,8 & 17,0 \\
\hline & Residuos Corr. Tip. & $-0,9$ & $-1,5$ & 1,8 & \\
\hline \multirow[t]{4}{*}{ Cibernautas } & $\mathrm{N}$ & 29 & 20 & 110 & 159 \\
\hline & $\%$ Fila & 18,2 & 12,6 & 69,2 & 100,0 \\
\hline & $\%$ Columna & 85,3 & 69,0 & 40,4 & 47,5 \\
\hline & Residuos Corr. Tip. & 4,7 & 2,4 & $-5,3$ & \\
\hline \multirow[t]{4}{*}{ Cibernautas participativos } & $\mathrm{N}$ & 1 & 7 & 111 & 119 \\
\hline & $\%$ Fila & 0,8 & 5,9 & 93,3 & 100,0 \\
\hline & $\%$ Columna & 2,9 & 24,1 & 40,8 & 35,5 \\
\hline & Residuos Corr. Tip. & $-4,2$ & $-1,3$ & 4,2 & \\
\hline \multirow[t]{3}{*}{ Total } & $\mathrm{N}$ & 34 & 29 & 272 & 335 \\
\hline & $\%$ Fila & 10,1 & 8,7 & 81,2 & 100,0 \\
\hline & $\%$ Columna & 100,0 & 100,0 & 100,0 & 100,0 \\
\hline
\end{tabular}

Fuente: Universidad de Los Lagos/Centro de Análisis de Redes Sociales (s/f), "Documentos de trabajo internos", Proyecto FondECYT $\left(\mathrm{N}^{\circ} 1120866\right)$ "El impacto de Internet en el capital social de las comunidades aisladas", Santiago.

\section{g) Del clientelismo al movimiento social}

En resumen, en el último medio siglo el capital social de las comunidades rurales de Aysén ha experimentado importantes cambios. Aunque las distintas formas específicas de capital social han estado presentes en toda época, algunas se han debilitado mientras que otras han acrecentado su presencia. Estas tendencias parecen relacionarse con la progresiva integración de 
las comunidades aisladas a la sociedad nacional y con cambios de orientación de los gobiernos centrales. En la sociedad civil, han aumentado las relaciones clientelares con dirigentes políticos. El efecto más común en cuanto al capital social colectivo ha sido una mayor división de las comunidades en facciones (Universidad de Los Lagos/Centro de Análisis de Redes Sociales, s/f; Astorga
2007). Pero a nivel personal, el efecto neto parece haber sido un incremento de capital social de redes, hacia niveles mayores de distancia geográfica y social. No obstante, las redes horizontales y las formas colectivas de capital social seguían vivas de manera "subsidente" (latente). Esta persistencia fue clave para el éxito del movimiento regional de 2012.

\section{IV}

\section{Movimiento regional "Tu problema es mi problema": el papel del capital social}

En los primeros días de febrero de 2012, una organización de pescadores artesanales convocó a otras organizaciones a una reunión en Puerto Aysén para proponerles un frente común de demandas (Miranda y Morales, 2012). A partir de esa reunión hubo una serie de marchas, barricadas y manifestaciones de miles de personas en las calles de ciudades y pueblos, que paralizaron a la región entera durante más de un mes. La rapidez con que emergió el movimiento social "Tu problema es mi problema" tomó por sorpresa al gobierno central, que reaccionó con represión policial. A la larga, el gobierno fue obligado a negociar y a aceptar muchas de las demandas del movimiento.

Virtualmente olvidado en el debate sobre capital social ha quedado el enfoque regional, a pesar de ser el aspecto central del libro que desencadenó la avalancha de estudios y debates. Robert Putnam, en Making Democracy Work (1993), argumentaba que la Región de Emilia-Romagna en Italia, por tener una sociedad dotada de abundante capital social, fue un caso exitoso de descentralización con gestión democrática regional de recursos públicos.

Entre los pocos estudios sobre capital social y movimientos regionalistas en América Latina están, en primer lugar, el trabajo de Fox (1996) sobre varias regiones en México. Fox traza el camino por el que se forja un movimiento popular regional a partir del capital social comunitario. Más recientemente, Cortés y Sinisterra (2009) exploran la relación entre capital social, movimiento social y buena gobernanza en la región del Cauca en Colombia, mientras que Burbano de Lara (2012) compara los movimientos autonomistas de Santa Cruz en Bolivia (Estado Plurinacional de) y Guayaquil en el
Ecuador, poniendo atención en el capital social de las oligarquías regionales.

El de Aysén es un movimiento "contencioso" (Tarrow, 1998), es decir, orientado a crear una contienda con el Estado, una impasse que le obliga a satisfacer sus demandas y escuchar sus propuestas. Esta contienda se desarrolló en una coevolución de estrategias de estos dos actores, llegando a ponerse en duda el cumplimiento del papel del Estado como garante de las condiciones (como vías de transporte, servicios básicos, orden público) para la vida económica en ese territorio. Al realizar un paro general ilegal y cortar las vías públicas con barricadas, el movimiento rompió con las reglas del juego establecidas e inició un "juego de las reglas"7. El gobierno empleó una estrategia de represión violenta, y el movimiento llevó a cabo una estrategia comunicacional de mostrar esa violencia, lo que despertó un alto apoyo de la opinión público nacional e internacional.

La literatura especializada ayuda a establecer y separar las categorías analíticas de capital social y movimiento social. Cortés y Sinisterra (2009) argumentan que un movimiento social es un fenómeno muy diferente del capital social: un movimiento es una acción colectiva, que puede tener mucho o poco capital social. Por otra parte, el de Aysén se diferencia de los movimientos de Santa Cruz y de Guayaquil en que estos fueron en gran parte iniciados por "oligarquías" (Burbano de Lara, 2012) regionales con discursos populistas. En Aysén, el

\footnotetext{
${ }^{7}$ El principal líder, sin embargo, fue candidato ganador de un escaño en la Cámara de Diputados nacional en 2013. Esta salida de y vuelta a las reglas del juego implicó un avance en la democratización de la vida política en Aysén.
} 
movimiento "Tu problema es mi problema", en contraste, nace y se moviliza en la base social de la región. La hipótesis emergente es que con la consolidación y el éxito de este movimiento emergió un actor social regional que aglutina a todos los sectores subalternos.

El estudio en terreno permite identificar tres aspectos de este movimiento en que el capital social ha jugado un papel: las organizaciones regionales preexistentes (capital social colectivo); las redes entre líderes (capital social interpersonal de puente) y la memoria social patagona (capital social "subsidente").

i) Organizaciones. El movimiento regional de 2012 pudo movilizar rápidamente a un gran número de personas en parte porque fue iniciado por varias organizaciones con capital social colectivo informal: es decir, normas informales y prácticas efectivas de rendición de cuentas (accountability) a sus bases. Los sindicatos de pescadores artesanales y de trabajadores en empresas pesqueras, la organización contra el macroproyecto hidroeléctrico, los transportistas y los empleados fiscales, que había logrado importantes movilizaciones en forma separada, también aportaron un alto cumplimiento en la huelga y las manifestaciones de esta causa común ${ }^{8}$.

El proyecto del cual este estudio forma parte se implementó en una muestra de siete comunidades con que se intenta ejemplificar la diversidad de aislamiento que se da en la región, cuyas organizaciones habían mostrado, cada una en forma individual, logros en huelgas, manifestaciones y negociaciones en años anteriores. También tenían, entre sí, objetivos radicalmente diferentes, algo característico de otros movimientos sociales en América Latina (De Sousa Santos, 2001). Pero en enero de 2012 comenzaron a reunirse los líderes de varias organizaciones para explorar sus puntos de convergencia en torno de la situación de la región (Universidad de Los Lagos/Centro de Análisis de Redes Sociales, s/f). En suma, la preexistencia de organizaciones con capital social colectivo fue un determinante del éxito del movimiento regional.

ii) Redes horizontales personales entre líderes. Datos para Aysén de 2006 arrojaron sobre un 70\% de personas que declararon contar con redes personales de

\footnotetext{
${ }^{8}$ Estas organizaciones tienen su razón de ser en la negociación con el Estado. Esto es evidente en la asociación de empleados fiscales, pero también ocurre en el caso de los sindicatos de pescadores artesanales (la semilla original del movimiento), creados bajo incentivos de la Ley de Pesca para negociar cuotas de captura con el Servicio Nacional de Pesca y Acuicultura (SERNAPESCA).
}

apoyo en caso de necesidad (ILPES/GORE, 2012). Y, como se ha visto, los habitantes de las comunidades rurales suelen tener vínculos de parentesco a través de la región.

A nivel regional, este mismo tipo horizontal de capital social de puente entre los principales líderes de "Tu problema es mi problema" que se conocían entre sí, constituyó una red interpersonal aun antes del surgimiento del movimiento regional (véase el gráfico 1). Las entrevistas realizadas con varios líderes regionales indican que el capital social de red, con cierre o traslape de reconocimiento mutuo entre estos líderes, puede explicar en gran medida la rapidez con que se expandió esta movilización.

iii) Capital social regional subsidente. Este concepto hace un símil entre un capital social latente y el retraimiento temporal del mar en la marea baja.

En el capital social subsidente se mantiene viva la "memoria social" de las experiencias de generaciones anteriores, transmitiéndose capacidades de organización empleadas en las antiguas comunidades (Astorga, 2007):

"La comunidad pasa por largos períodos de letargo e inactividad [pero] ante una amenaza externa el pueblo vuelve a asumir un rol protagónico temporal" (Universidad de Los Lagos/Centro de Análisis de Redes Sociales, s/f).

Otra forma de capital social subsidente es la capacidad, siempre latente, de movilizarse en torno de un objetivo socioterritorial. Se mantiene una clara identidad aysenina y, más ampliamente, "patagona", ligada al hecho de haber nacido en la Patagonia y a una constelación de normas y valores compartidos. Es un proceso identitario colectivo por medio de la distinción entre nosotros y los otros (Barth, 1969). Los nacidos en la región excluyen a la "gente nueva" que no es patagona, y en segundo lugar, excluye a los que no practican el habitus pionero de generosidad, reciprocidad y solidaridad, o sea, a "los ricos". Así, la alteridad es clara:

"[Los de afuera] vienen en un buen nivel de vida... llegan acá y comienzan a vivir en el centro, forman un círculo con todos profesionales..., se aíslan total y completamente de las poblaciones... entonces hay como la convivencia de dos mundos" (Universidad de Los Lagos/Centro de Análisis de Redes Sociales, s/f).

Se plantea, entonces, que estas tres formas de capital social subsidente: la memoria social de acción colectiva, las redes interpersonales intercomunitarias e interorganizacionales y la identidad colectiva patagona contribuyeron a la fuerza del movimiento "Tu problema es mi problema". 
GRÁFICO 1

\section{Red de conocidos entre líderes, antes de enero de 2012}

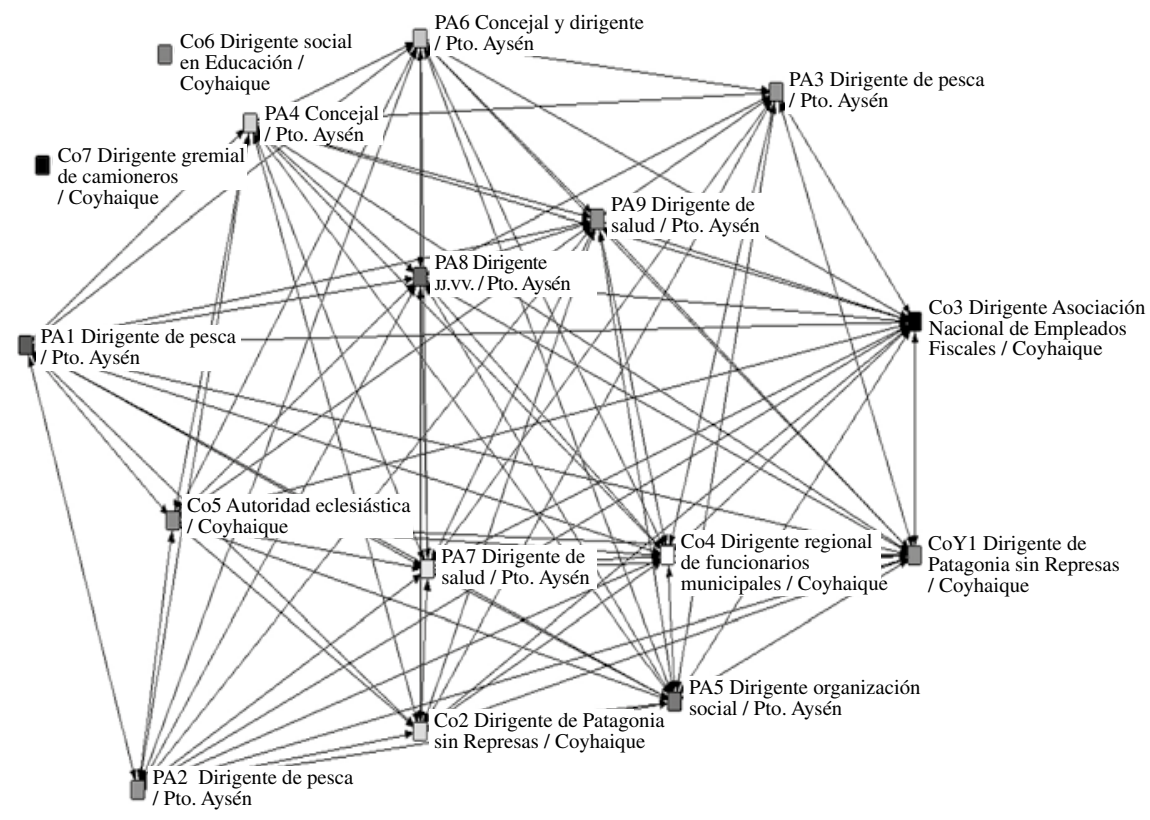

Fuente: Elaboración propia sobre la base de entrevistas y método de análisis de redes sociales procesado con el programa UCINET.

\section{El papel de Internet en el movimiento}

Internet es, sin duda, la tecnología que más avance potencial ofrece a los movimientos sociales que se basan en el trabajo en redes. Ya en el período 2009-2011, Internet fue clave en la coordinación y el financiamiento de "Patagonia sin Represas", un importante movimiento antihidroeléctrica a niveles de la región, del país e internacional (Astorga, 2013). Sin embargo, debido en parte a la incipiente cobertura de Internet en el campo, en 2012 los habitantes rurales se informaron del movimiento "Tu problema es mi problema" principalmente por medio de la radio, la que jugó el papel central de convocatoria amplia:

"Acá hay mucha gente que vive en localidades del campo, que lo único que llega es la radio a pila... la radio desde siempre ha tenido harto vínculo con la gente y con los dirigentes sociales" (Universidad de Los Lagos/Centro de Análisis de Redes Sociales, s/f). No obstante, Internet sí tuvo un doble papel en el éxito de este movimiento. En primer lugar, los cibernautas-participativos de las comunidades rurales tuvieron un $41 \%$ de participación en, o de apoyo a, los movimientos sociales vía Internet, casi el doble de la tasa de los cibernautas "puros" (véase el cuadro 3). Este subconjunto de vecinos también participa en un $100 \%$ en organizaciones locales. En suma, los cibernautas- participativos sirvieron de vínculo entre dos niveles de capital social colectivo: el de la comunidad local y el de las organizaciones regionales.

En segundo lugar, los jóvenes profesionales con experiencia en Internet de "Patagonia sin Represas" jugaron un papel clave en el desarrollo de una capacidad mediática del movimiento regional "Tu problema es mi problema". Los dirigentes de los pescadores artesanales, obreros de bajos ingresos, tenían pocos conocimientos de Internet. La práctica comunicacional inicial del movimiento consistió en ir a las radios locales y pegar carteles en los muros de Puerto Aysén llamando a participar en la primera marcha. Pero a los pocos días la adhesión de "Patagonia sin Represas" al nuevo movimiento posibilitó un salto cualitativo en el impacto en la opinión pública nacional.

“... [F]ue un tremendo aporte para el movimiento de [la gente de] 'Patagonia sin Represas'... Se maneja con los medios, entonces lo que decíamos lo enviaba [por internet] a distintos diarios..." (Universidad de Los Lagos/Centro de Análisis de Redes Sociales, s/f).

Los principales medios nacionales tendían a reproducir los comunicados del gobierno y daban poco espacio a las denuncias del movimiento sobre, por ejemplo, la violencia policial. Pero el uso de todos los 
CUADRO 3

¿Con qué frecuencia utiliza usted Internet, y participa o apoya las movilizaciones sociales?

\begin{tabular}{|c|c|c|c|c|}
\hline & & Nunca & Al menos, alguna vez & Total \\
\hline \multirow[t]{3}{*}{ Participativos } & $\mathrm{N}$ & 51 & 6 & 57 \\
\hline & $\%$ Fila & 89,5 & 10,5 & 100,0 \\
\hline & Residuos Corr. Tip. & 3,1 & $-3,1$ & \\
\hline \multirow[t]{3}{*}{ Cibernautas } & $\mathrm{N}$ & 119 & 35 & 154 \\
\hline & $\%$ Fila & 77,3 & 22,7 & 100,0 \\
\hline & Residuos Corr. Tip. & 1,7 & $-1,7$ & \\
\hline \multirow[t]{3}{*}{ Cibernautas participativos } & $\mathrm{N}$ & 69 & 48 & 117 \\
\hline & $\%$ Fila & 59,0 & 41,0 & 100,0 \\
\hline & Residuos Corr. Tip. & $-4,2$ & 4,2 & \\
\hline \multirow[t]{2}{*}{ Total } & $\mathrm{N}$ & 239 & 89 & 328 \\
\hline & $\%$ Fila & 72,9 & 27,1 & 100,0 \\
\hline
\end{tabular}

Fuente: Universidad de Los Lagos/Centro de Análisis de Redes Sociales (s/f), "Documentos de trabajo internos", Proyecto FONDECYT $\left(\mathrm{N}^{\circ}\right.$ 1120866) "El impacto de Internet en el capital social de las comunidades aisladas", Santiago.

recursos de Internet, desde correos electrónicos hasta blogs y Facebook, condujo a una amplísima difusión viral entre los usuarios de estas redes sociales virtuales. Facebook, en especial, permitió impactar en la opinión pública con videos de entrevistas con líderes y de la represión policial.

Pero no fue Internet por sí solo la clave comunicacional del éxito del movimiento: hubo una dinámica compleja de imbricación entre las TIC tradicionales (radio, TV, diarios) y las modernas. Y el uso de Twitter - la aplicación de Internet de microblogging que posibilita enviar mensajes cortos que pueden llegar en forma viral a un sinnúmero de usuarios-en teléfonos móviles permitió: i) coordinar una respuesta rápida y movilizadora del movimiento frente a tácticas represoras, y ii) comunicar al país y al mundo las demandas del movimiento, las adhesiones a la huelga y la represión policial:

“... los carabineros estaban tirando bombas y todo eso, y eso se supo a través de Facebook, [por personas] que estaban adentro conectados o con

\section{V}

\section{Conclusiones}

Distinguir entre diferentes tipos de capital social ha permitido elaborar en este trabajo nuevas hipótesis sobre su evolución en la Región de Aysén y su papel en los cambios en la sociedad civil. En este artículo
iPhone o esas cosas, y nosotros [en la radio] nos colgábamos de mucha de esa información... en la tele no salía nada, entonces icuánto se presionó desde este humilde medio de comunicación!'(Universidad de Los Lagos/Centro de Análisis de Redes Sociales, $\mathrm{s} / \mathrm{f})^{9}$.

En resumen, a pesar de la incompleta cobertura de Internet en las comunidades rurales de Aysén y de la exclusión digital de los estratos de bajos ingresos, fue gracias a esta imbricación entre medios y tecnologías que Internet desempeñó un papel clave en el éxito final del movimiento regional, potenciando la comunicación tanto hacia los actores en el nivel local como hacia la opinión pública a nivel nacional, en complemento con las TIC tradicionales.

\footnotetext{
${ }^{9}$ La emisión en vivo por Internet de la Radio Santa María de Coyhaique era seguida por periodistas y activistas regionales, nacionales e internacionales.
}

se ha presentado un seguimiento, situado histórica y socialmente, de las distintas formas de capital social que florecieron en cuatro momentos de la sociedad civil regional. Los auges de diversos tipos de capital 
social se han sucedido en consonancia con la progresiva conectividad en transporte y comunicaciones, en épocas diferentes de políticas públicas del gobierno central.

Hace más de 50 años, época de comunidades altamente aisladas y con baja presencia del Estado, en la composición de capital social hubo predominio de capital social de redes horizontales que reforzaban las acciones colectivas comunitarias. Estas redes fueron debilitadas posteriormente por la represión o cooptación de toda forma de capital colectivo. Con el regreso a la democracia electoral tuvo lugar un auge del clientelismo; finalmente, a partir de 2012, las diversas formas de capital social subsidente fueron reactivadas por un movimiento regional.

El movimiento de 2012 no parece ser un evento aislado en el tiempo, sino que marca un antes y un después en la sociedad civil de Aysén y en las formas de capital social que la sustentan. Si bien su incidencia en las políticas públicas fue limitada en el primer año (Pérez, 2014) y el movimiento volvió a un estado de relativa "subsidencia", las organizaciones de base regionales mantuvieron vivas sus demandas y el Estado central, junto con el Congreso Nacional, colocó los cimientos de una política de Estado para esta y otras "zonas extremas". En el marco de una nueva ley para estas regiones, con respecto al período 2012-2015 el presupuesto público para Aysén aumentó en un 67\% (Universidad de Los Lagos/Centro de Análisis de Redes Sociales, s/f).

El movimiento contencioso de Aysén es un caso digno de consideración y comparación, primero porque es un caso de participación desde la base (bottom-up) no dominada por "oligarquías regionales"; segundo, porque marcó el paso de actores con capital social "en" el territorio regional a un actor popular "del" territorio a nivel regional. Si bien ya existían organizaciones locales y a nivel de la región con capital social colectivo, el movimiento de 2012 hizo emerger un actor social subalterno amplio con presencia regional, capaz de hacer el peso a actores en posiciones sociales de mayor poder.

La relevancia de un análisis de las diversas formas de capital social para la implementación de una descentralización electoral y administrativa ya no admite duda:

“... a mayor capital social de respaldo de su legitimidad, refrendado en relaciones de lealtad y/o confianza de las organizaciones sociales hacia ellos, mayor será la probabilidad de protagonismo de estos actores en un eventual proceso descentralizado" (De la Maza, Cunhill y Joignant, 2012).

Putnam (1993) mostró, en el caso de la descentralización regional italiana, que el capital social importa en los resultados de tal proceso, sea para aumentar el bienestar general o, en su ausencia, para alimentar la desigualdad. La experiencia de Aysén conduce a los autores del presente estudio a proponer que este enfoque se pueda aplicar en otras regiones que se beneficien - potencialmente al menos- de la descentralización. Las lecciones de Aysén, exitosas en la democratización de su sociedad civil, dan pistas para fortalecer el capital social de potenciales actores colectivos subalternos, como parte integral de la descentralización.

\section{Bibliografía}

Astorga, E. (2013), "Conflicto ambiental en Patagonia: observaciones sobre la comunicación medioambiental en la región de Aysén a raíz del proyecto Hidroaysén", tesis, Santiago, Universidad de Chile.

(2007), "Puerto Guadal y Puerto Bertrand: una mirada antropológica hacia la historia de las relaciones sociales que hoy en día generan una escasa participación de las personas en proyectos de desarrollo local", tesis, Santiago, Tesis de Licenciatura en Antropología, Santiago, Universidad Academia de Humanismo Cristiano.

Atria, R. (2003), "Capital social: concepto, dimensiones y estrategias para su desarrollo", Capital social y reducción de la pobreza: en busca de un nuevo paradigma, Libros de la CEPAL, $\mathrm{N}^{\circ} 71$ (LC/G.2194-P), R. Atria y otros (comps.), Santiago, Comisión Económica para América Latina y el Caribe (CEPAL).

Auyero, J. (2001), La política de los pobres: las prácticas clientelistas del peronismo, Buenos Aires, Manantial.

Barth, F. (1969), "Introduction”, Ethnic Groups and Boundaries: The Social Organization of Culture Difference, Oslo, Universitetsforlaget.

Bourdieu, P. (2001), Las estructuras sociales de la economía, Buenos Aires, Ediciones Manantial.
Bourdieu, P. y M. de Saint Martin (1978), "Le patronat", Actes de la recherche en sciences sociales, vol. 20-21, $\mathrm{N}^{\circ} 1$, París, Seuil.

Burbano de Lara, F. (2012), "Movimientos regionales y autonomías políticas en Bolivia y Ecuador", tesis, Universidad de Salamanca [en línea] http://gredos.usal.es/jspui/bitstream/10366/115574/1/ DDPG_Burbano_de_Lara_F._Movimientos_Regionales.pdf.

Cortés, R. y M. Sinisterra (2009), "Colombia: capital social, movilización social y sostenibilidad del desarrollo en el Cauca", Revista CEPAL, № 99 (LC/G.2418-P), Santiago, diciembre.

De la Maza, G., N. Cunhill y A. Joignant (2012), "La descentralización: asunto de actores y su articulación”, Nueva agenda de descentralización en Chile: sentando más actores a la mesa, $\mathrm{G}$. de la Maza, N. Cunhill y A. Jognant (eds.), Santiago, RIL Editores.

De Sousa Santos, B. (2001), "Los nuevos movimientos sociales", Observatorio Social de América Latina, $\mathrm{N}^{\circ}$ 5, Buenos Aires, Consejo Latinoamericano de Ciencias Sociales (CLACSO).

Ejército de Chile (2013), "Presidente de la República clausuró Seminario sobre zonas aisladas y soberanía efectiva” [en línea] http://www.defensa.pe/forums/showthread.php/5413-Noticiasdel-Ejercito/page37.

Farr, J. (2004), "Social capital: a conceptual history", Political Theory, vol. 32, $\mathrm{N}^{\circ}$ 1, SAGE Publications. 
Ferlander, S. y D. Timms (2007), "Social capital and community building through the Internet: a Swedish case study in a disadvantaged suburban area", Sociological Research Online, vol. 12, $\mathrm{N}^{\circ} 5$ [en línea] http://www.socresonline.org.uk/12/5/8. html.

Foth, M. (2003), "Connectivity does not ensure community: on social capital, networks and communities of place" [en línea] http:// eprints.qut.edu.au/1902/1/1902.pdf.

Fox, J. (1996), "How does civil society thicken? The political construction of social capital in rural Mexico", World Development, vol. 24, № 6, Amsterdam, Elsevier.

Fukuyama, F. (2003), "Capital social y desarrollo: la agenda venidera", Capital social y reducción de la pobreza: en busca de un nuevo paradigma, Libros de la CEPAL, $\mathrm{N}^{\circ} 71$ (LC/G.2194-P), R. Atria y otros (comps.), Santiago, Comisión Económica para América Latina y el Caribe (CEPAL).

Grootaert, Ch. (1998), Social Capital: The Missing Link?, Washington, D.C., Banco Mundial.

Hanifan, L. (1920), The Community Center, Boston, Silver, Burdette $\&$ Co.

Hardin, G. (1968), "The tragedy of the commons", Science, vol. 162, $\mathrm{N}^{\circ} 3859$.

ILPES/GORE (Instituto Latinoamericano y del Caribe de Planificación Económica y Social/Gobierno Regional de Aysén) (2012), Estrategia regional de desarrollo de Aysén, Santiago, Comisión Económica para América Latina y el Caribe (CEPAL).

Martinic, M. (2005), De la Trapananda al Aysén. Una mirada reflexiva sobre el acontecer de la Región de Aysén desde la prehistoria hasta nuestros días, Santiago, Pehuén Editores.

Miranda, F. y A. Morales (2012), "Movimiento ciudadano: Aysén, tu problema es mi problema”, S. Gómez (comp.), Santiago, Universidad Academia de Humanismo Cristiano/Grupo de Investigaciones Agrarias.

Molenaars, N. (2006), "Vida asociativa y desarrollo local en dos pueblos nicaragüenses", Revista CEPAL, N ${ }^{\circ} 90$ (LC/G.2323-P), Santiago, diciembre.

Ostrom, E. (2000), El gobierno de los bienes comunes. La evolución de las instituciones de acción colectiva, Ciudad de México, Fondo de Cultura Económica.

Pérez, M. (2014), "Movimiento social de Aysén: un caso de análisis de incidencia ciudadana en la agenda de políticas públicas", tesis, Santiago, Universidad de Chile [en línea] http://www. internetycapitalsocial.cl/.

Portes, A. (1998), "Social capital: its origins and applications in modern sociology", Annual Review of Sociology, vol. 24.

Putnam, R. (1993), Making Democracy Work: Civic Traditions in Modern Italy, Princeton, Princeton University Press.

Salazar, G. (2001), "Memoria histórica y capital social", Capital social y políticas públicas en Chile, J. Durston y F. Miranda, serie Políticas Sociales, N ${ }^{\circ} 55$ (LC/L.1606-P), Santiago, Comisión Económica para América Latina y el Caribe (CEPAL).

Subdere (Subsecretaría de Desarrollo Regional) (2013), "Metodología para la identificación de localidades en condición de aislamiento", Santiago [en línea] http://www.subdere.gov. cl/sites/default/files/documentos/metodologia_03072013.pdf.

Tarrow, S. (1998), Power in Movement: Social Movements and Contentious Politics, Cambridge, Cambridge University Press.

Universidad de Los Lagos/Centro de Análisis de Redes Sociales (s/f), "Documentos de trabajo internos", Proyecto FONDECYT $\left(\mathrm{N}^{\circ} 1120866\right)$ "El impacto de Internet en el capital social de las comunidades aisladas", Santiago.

Uphoff, N. (2003), "El capital social y su capacidad de reducción de la pobreza", Capital social y reducción de la pobreza: en busca de un nuevo paradigma, Libros de la CEPAL, $\mathrm{N}^{\circ} 71$ (LC/G.2194-P), R. Atria y otros (comps.), Santiago, Comisión Económica para América Latina y el Caribe (CEPAL).

Valenzuela, A. (1977), Political Brokers in Chile, Durham, Duke University Press.

Wellman, B. (2005), "Lugar físico y lugar virtual: el surgimiento de las redes personalizadas", Redes: enfoques y aplicaciones del análisis de redes sociales, J.I. Porras y V. Espinoza (eds.), Santiago, Universidad Bolivariana/Universidad de Santiago de Chile.

Wolf, E.R. (1966), "Kinship, friendship and patron-client relationships in complex societies", The Social Anthropology of Complex Societies, M. Banton (comp.), Londres, Tavistock Publications.

Woolcock, M. y D. Narayan (2000), "Social capital: implications for development theory, research and policy", World Bank Research Observer, vol. 15, $\mathrm{N}^{\circ}$ 2, Washington, D.C., Banco Mundial. 